\title{
Relationship between Gender Roles and Job Satisfaction among Neurological Physical Therapists
}

\author{
Ji-Whan Park, PhD, PT • Seul-Ki Han PhD, PT ${ }^{1 \dagger} \cdot$ Dae-Hee Lee, PhD, PT ${ }^{1}$ \\ Department of Physical Therapy, Daejeon Health Sciences College \\ ${ }^{1}$ Department of Physical Therapy, U1 University
}

Received: July 3, 2016 / Revised: July 8, 2016 / Accepted: July 30, 2016

(C) 2016 J Korean Soc Phys Med

\begin{abstract}
| Abstract |
PURPOSE: This study was aimed at investigating the types of gender roles and the relationship between gender roles and job satisfaction among neurological physical therapists.
\end{abstract}

METHODS: The study subjects were 169 (male 74, female 95) neurological physical therapists working at general hospitals or rehabilitation centers in the Daejeon Metropolitan City area, South Korea. To identify job satisfaction scores, the subjects completed a questionnaire, and a vernier caliper was used by a trained examiner to measure the lengths of the subjects' index and ring fingers (i.e., digitus secundus manus and digitus annularis, respectively) to examine gender roles. The index to ring finger length ratio (i.e., 2D:4D ratio) was calculated using a personal computer. An independent t-test was performed to compare the finger length ratio and job satisfaction of male group with that of the female group and a correlation analysis was performed to examine job satisfaction by gender roles.

†Corresponding Author : lovewisd@ul.ac.kr

This is an Open Access article distributed under the terms of the Creative Commons Attribution Non-Commercial License (http://creativecommons.org/licenses/by-nc/3.0) which permits unrestricted non-commercial use, distribution, and reproduction in any medium, provided the original work is properly cited.
RESULTS: Finger length ratio is lower in males than in females. However, there was no significant difference statistically ( $>.05$ ). Regarding job satisfaction by gender, males were more satisfied with their jobs than females $(\mathrm{p}<.05)$. However, there were no significant correlations between job satisfaction and gender roles ( $p>05$ ).

CONCLUSION: It cannot be concluded that bias against gender roles is a contributing factor for neurological physical therapists being satisfied with their job, and thus bias against gender roles among neurological physical therapists should be removed.

Key Words: Finger length ratio, Gender roles, Job satisfaction, Neurological physical therapists

\section{Introduction}

Neurological physical therapist is a job profile that can expectedly serve to improve hospital profitability and enable efficient hospital management when exercising leading capability in the neurological therapy field (Jang et al., 2010). Therefore, accurate understanding of the nature of the job as a neurological physical therapist is an important task that can enhance the quality of medical 
services and improve patient satisfaction (Kim et al., 2004; Park, 2004; Lim et al., 2010).

Gender roles are a major factor among various factors in determining the nature of each job (Jo, 2009). Gender roles are attributed to social gender differences, regardless of biological gender (Lee, 2004; Park et al., 2014). In addition, gender roles are under the influence of sex hormones from the prenatal period, and sex hormones influence the finger length ratio of the index finger length to the ring finger length. In other words, a ratio closer to $100 \%$ is considered more feminine (Evardone et al., 2008; Jeon et al., 2010).

If individuals choose their professional field in consideration of such gender roles, they may be more satisfied with their job and have a more positive attitude toward career development (Lee, 2002). Meanwhile, it has been reported that gender roles might not be correlated with choosing one's professional field (Park, 2008). Thus, appropriate gender roles may or may not exist for each job.

If correlations between gender roles of neurological physical therapists and their job satisfaction are found, it can be considered as to whether their occupational field is suited to their gender role, thereby contributing toward enhancing their overall job satisfaction (Jo, 2008). In addition, it serves as empirical evidence for some people who have prejudices against the gender roles of neurological physical therapists, thus removing their prejudices.

Lim et al. (2003) reported that there were gender-specific differences between the sociodemographic variables of professionalism and organizational citizenship behavior of physical therapists, while Park (2012) reported that there were gender-specific differences between the fields of interest and preferred work forms of physical therapy students. Howevere, studies on gender roles and job satisfaction among neurological physical therapists are lacking.
This study was aimed at investigating the types of gender roles and the relationship between gender roles and job satisfaction among neurological physical therapists.

\section{Methods}

\section{Subjects}

The study subjects were 169 (male 74, female 95) neurological physical therapists working at general hospitals or rehabilitation centers in the Daejeon Metropolitan City area, South Korea. All subjects were fully informed of the objectives and methods of the study beforehand, and informed consent to participate in the experiments was obtained from them. General characteristics of the study subjects was as Table 1 .

Table 1. Demographic characteristics of the subjects

\begin{tabular}{ccc}
\hline & & Frequency(\%) \\
\hline \multirow{2}{*}{ Gender } & Man & $74(43.79)$ \\
& Woman & $95(56.21)$ \\
\hline \multirow{2}{*}{ Age } & Under 30 yrs & $110(65.09)$ \\
& $30 \sim 40$ yrs & $59(34.91)$ \\
\hline \multirow{2}{*}{ Career } & Under 5 yrs & $110(65.09)$ \\
& $6 \sim 10$ yrs & $59(34.91)$ \\
\hline \multirow{2}{*}{ Marital status } & Single & $133(78.70)$ \\
& Married & $36(21.30)$ \\
\hline \multirow{2}{*}{ Salary } & Under $\# 1,500$ & $27(15.95)$ \\
(thousand) & \#2,001 2,501 2,000 & $69(40.83)$ \\
& Above $\# 2,500$ & $51(30.18)$ \\
& & $22(13.02)$ \\
\hline
\end{tabular}

\section{Measurement methods and data collection}

Measurer measured the length of the finger of the subject. Job satisfaction survey proceeded in the 1) visit passed, 2) self-written, 3) direct collection. The recovery rate was $100 \%$. 
1) Finger length ratio

The length measurement of the finger was reference to the method of Manning et al. (2000) (Fig. 1). Vernier caliper was used by a trained examiner to measure the lengths of the subjects' index and ring fingers to examine gender roles. Inter-examiner and intra-examiner reliability was .95 and .96 . The finger length ratio used in this study was calculated using the following formula (Bailey and Hurd, 2005). Subjects raised dominant hands on the table. Than, examiners measured the shortest distance from the the ventral proximal crease central point to central point finger tip of index and ring finger.

$$
\text { Ratio of finger length }(\%)=\frac{\text { length of } 2 D(\mathrm{~cm})}{\text { length of } 4 D(\mathrm{~cm})}
$$

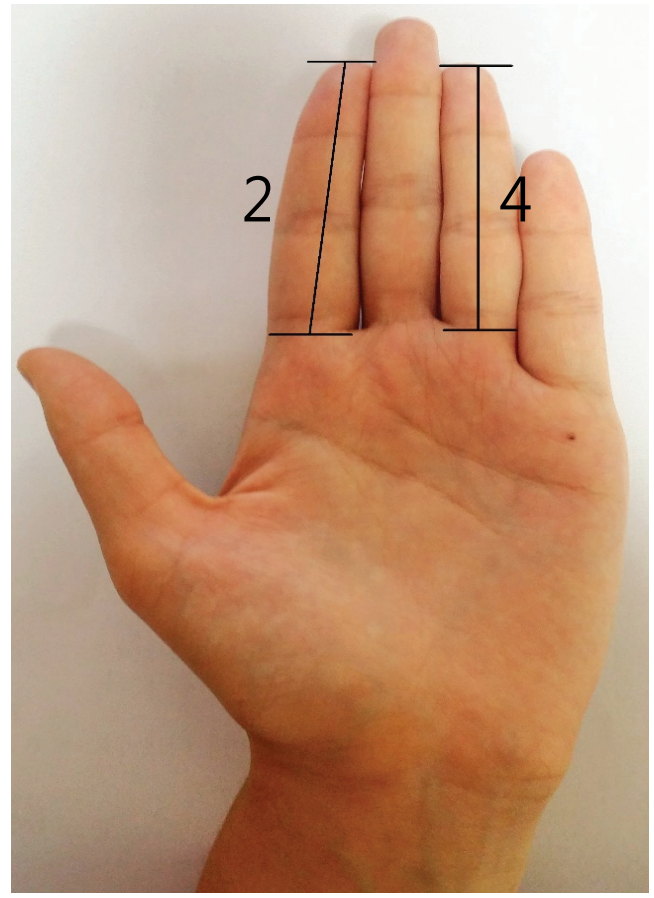

Fig. 1. length measurement of the finger

\section{2) Job satisfaction}

A questionnaire about job satisfaction used in the present study was adapted from a study by Lee (2013). Through preliminary research, it was to confirm the 10 questions. This survey was the Cronbach Alpha Coefficient of .81.

The following were questionnaire content. We asked 1) pride and fulfillment of occupation (pride), 2) conformity to current fields and aptitude (aptitude match), 3) occupation satisfaction of fields (fields satisfaction), 4) satisfaction of workload (workload) and 5) satisfaction of job (satisfaction) to see if subjects were satisfied with field and job. The higher the score of pride, subjects prided in fields. The higher the score of aptitude match, aptitude of subjects were matched field. The higher the score of fields satisfaction, subjects were satisfied with field. The higher the score of workload, subjects were satisfied with workload. The higher the score of satisfaction, subjects were satisfied with job.

We asked satisfaction of 6) salary (salary satisfaction) and 7) salary satisfaction compared with workload (salary-workload) to see if subjects were satisfied with salary. The higher the score of salary satisfaction, subjects were satisfied with salary. The higher the score of salary-workload, subjects were satisfied with salary when compared with salary.

We asked 8) reflection of opinions (reflection), 9) development of ability (development) and 10) demonstration of ability (demonstration) to see if subjects were satisfied with ability to work.

The higher the score of reflection, subjects were satisfied that their opinions will be reflected in institutions. The higher the score of development, subjects was satisfied with their ability to develop. The higher the score of demonstration, subjects were satisfied that their ability will be demonstrated in institutions.

\section{Analysis}

SPSS 12.0 was used for the statistical analysis, with a significance level of .05 . An independent t-test was performed to compare the finger length ratio and job satisfaction of male group with that of the female group 
and a pearson's correlation analysis was performed to examine job satisfaction by gender roles.

\section{Results}

\section{Finger length ratio according to gender}

Finger length ratio is lower in males than in females. However, there was no significant difference statistically (p>.05) (Table 2).

Table 2. 2D:4D difference comparison according to field and gender

(unit: \%)

\begin{tabular}{cc}
\hline & Mean \pm SD \\
\hline Total & $97.35 \pm 3.80$ \\
Male & $96.96 \pm 3.60$ \\
Female & $97.65 \pm 3.95$ \\
$\mathrm{t}$ & -1.17 \\
$\mathrm{p}$ & .25 \\
\hline
\end{tabular}

\section{Job satisfaction according to gender}

The males in all categories of job satisfaction was higher than females. And pride, aptitude match, workload, satisfaction, salary satisfaction, reflection, development and demonstration was a significant difference statistically significant $(\mathrm{p}<.05)$ fields satisfaction and salary workload was not significantly different statistically $(\mathrm{p}>.05)$ (Table 3 ).

\section{Correlation between finger length ratio and job satisfaction}

There was no significant correlation between finger length ratio and job satisfaction. (p>.05) (Table 4).

\section{Discussion}

This study was aimed at investigating the types of gender roles and the relationship between gender roles and job satisfaction among neurological physical therapists.

Kim and Kim (2010) reported that finger length ratios were $94 \%$ in male university students and $97 \%$ in female university students. In addition, Kim and Jo (2012) found that finger length ratios were $95 \%$ in male healthcare college students, $96 \%$ in their female counterparts, and that there were significant differences in finger length ratios by gender. In contrast, the present study found that finger

Table 3. Job satisfaction grade comparison according to field

(unit: score)

\begin{tabular}{|c|c|c|c|c|}
\hline & \multicolumn{2}{|c|}{ Mean \pm SD } & \multirow{2}{*}{$\mathrm{t}$} & \multirow{2}{*}{$\mathrm{p}$} \\
\hline & males & females & & \\
\hline pride $^{1)}$ & $3.72 \pm .94$ & $3.38 \pm .77$ & 2.55 & $.01^{*}$ \\
\hline aptitude match & $3.59 \pm 1.02$ & $3.24 \pm .77$ & 2.48 & $.02^{*}$ \\
\hline fields satisfaction & $3.50 \pm .97$ & $3.25 \pm .77$ & 1.80 & .08 \\
\hline workload & $3.28 \pm 1.13$ & $2.68 \pm .88$ & 3.77 & $<.01^{* *}$ \\
\hline satisfaction & $3.59 \pm 1.05$ & $3.21 \pm .81$ & 2.61 & $.01^{*}$ \\
\hline salary satisfaction & $2.54 \pm 1.08$ & $2.23 \pm .88$ & 2.05 & $.04^{*}$ \\
\hline salary workload & $3.12 \pm 1.06$ & $2.88 \pm 1.1$ & 1.42 & .16 \\
\hline reflection & $3.19 \pm .9$ & $2.80 \pm .77$ & 3.03 & $<.01^{* *}$ \\
\hline development & $3.53 \pm .85$ & $3.24 \pm .71$ & 2.33 & $.02^{*}$ \\
\hline demonstration & $3.51 \pm .91$ & $3.17 \pm .71$ & 2.69 & $<.01^{* *}$ \\
\hline
\end{tabular}

\footnotetext{
${ }^{1)}$ refer to the table $2 .{ }^{*} \mathrm{p}<.01,{ }^{* *} \mathrm{p}<.05$
} 
Table 4. 2D:4D difference and job satisfaction grade correlation

(unit: score)

\begin{tabular}{|c|c|c|c|c|c|c|}
\hline & \multicolumn{2}{|c|}{ total } & \multicolumn{2}{|c|}{ male } & \multicolumn{2}{|c|}{ female } \\
\hline & mean \pm SD & $\mathrm{r}(\mathrm{p})$ & mean \pm SD & $\mathrm{r}(\mathrm{p})$ & mean $\pm \mathrm{SD}$ & $\mathrm{r}(\mathrm{p})$ \\
\hline pride $^{1)}$ & $4.06 \pm .87$ & $\begin{array}{c}.01 \\
(.95)\end{array}$ & $3.72 \pm .94$ & $\begin{array}{l}-.11 \\
(.35)\end{array}$ & $3.38 \pm .77$ & $\begin{array}{c}.14 \\
(.18)\end{array}$ \\
\hline aptitude match & $4.00 \pm .90$ & $\begin{array}{c}-.04 \\
(.60)\end{array}$ & $3.59 \pm 1.02$ & $\begin{array}{l}-.08 \\
(.47)\end{array}$ & $3.24 \pm .77$ & $\begin{array}{c}.03 \\
(.75)\end{array}$ \\
\hline fields satisfaction & $3.94 \pm .87$ & $\begin{array}{l}-.04 \\
(.61)\end{array}$ & $3.50 \pm .97$ & $\begin{array}{l}-.22 \\
(.05)\end{array}$ & $3.25 \pm .77$ & $\begin{array}{c}.15 \\
(.15)\end{array}$ \\
\hline workload & $3.50 \pm 1.04$ & $\begin{array}{l}-.04 \\
(.63)\end{array}$ & $3.28 \pm 1.13$ & $\begin{array}{l}-.18 \\
(.13)\end{array}$ & $2.68 \pm .88$ & $\begin{array}{c}.14 \\
(.18)\end{array}$ \\
\hline satisfaction & $4.06 \pm .94$ & $\begin{array}{l}-.05 \\
(.53)\end{array}$ & $3.59 \pm 1.05$ & $\begin{array}{l}-.09 \\
(.44)\end{array}$ & $3.21 \pm .81$ & $\begin{array}{c}.02 \\
(.83)\end{array}$ \\
\hline salary satisfaction & $2.69 \pm .98$ & $\begin{array}{l}-.06 \\
(.46)\end{array}$ & $2.54 \pm 1.08$ & $\begin{array}{l}-.06 \\
(.60)\end{array}$ & $2.23 \pm .88$ & $\begin{array}{l}-.03 \\
(.78)\end{array}$ \\
\hline salary workload & $3.06 \pm 1.09$ & $\begin{array}{l}-.02 \\
(.77)\end{array}$ & $3.12 \pm 1.06$ & $\begin{array}{l}-.14 \\
(.23)\end{array}$ & $2.88 \pm 1.1$ & $\begin{array}{c}.07 \\
(.47)\end{array}$ \\
\hline reflection & $3.00 \pm .85$ & $\begin{array}{l}-.08 \\
(.32)\end{array}$ & $3.19 \pm .90$ & $\begin{array}{l}-.02 \\
(.86)\end{array}$ & $2.8 \pm .77$ & $\begin{array}{l}-.09 \\
(.38)\end{array}$ \\
\hline development & $3.38 \pm .78$ & $\begin{array}{c}-.01 \\
(.95)\end{array}$ & $3.53 \pm .85$ & $\begin{array}{l}-.07 \\
(.58)\end{array}$ & $3.24 \pm .71$ & $\begin{array}{c}.08 \\
(.46)\end{array}$ \\
\hline demonstration & $3.63 \pm .82$ & $\begin{array}{l}-.05 \\
(.55)\end{array}$ & $3.51 \pm .91$ & $\begin{array}{l}-.09 \\
(.46)\end{array}$ & $3.17 \pm .71$ & $\begin{array}{c}.03 \\
(.81)\end{array}$ \\
\hline
\end{tabular}

${ }^{1)}$ refer to the table 2 .

length ratios were $96 \%$ in males and $97 \%$ in females. Although smaller in males than in females, there was no statistically significant difference between both sexes. The results of the present study indicated that male neurological physical therapists had a relatively more feminine disposition. Similarly Kim and Jo (2012) described male university students with a health science major as having a more feminine disposition compared with university students with a different major, and Jung (2002) described that when choosing a career, it is difficult for individuals to choose a career opposed to their gender role. As the results of both previous studies and the present study indicate, a physical therapist's job is perceived as being a relatively feminine job, thus male students, with a different type rather than masculine type, have applied to the Departments of Physical Therapy at universities.
Consequently, a smaller number of neurological physical therapists with masculine type are supposed to enter into clinical practice, and the finger length ratios in male neurological physical therapists were found to be close to those of their female counterparts. Therefore, it is thought that there was no significant difference in finger length ratios between male and female neurological physical therapists.

The results of this study, males in all categories of job satisfaction was higher than females. The results of many previous studies are consistent with and support the results of the present study (Bae et al., 2011; Lee et al., 2005; Sim and Yoon, 2011). In this regard, Lim et al. (2003) described that the reason why males are more satisfied with their jobs than females are, is because males have a high recognition of life-long career, and Cho (2013) 
described that males have a significantly higher positive self-esteem factor than females do. Therefore, many physical therapies, especially those involving female physical therapists, should be provided with a variety of programs to boost self-esteem. In contrast, Park (2012) and Sin (2010) stated that males prefer occupational fields that they want, whereas females prefer stable occupational fields in which employment can be easily obtained and those that have the advantage of long-term service. On the other hand, Jung (2010) was no difference in job satisfaction according to gender. And many studies about job satisfaction among physical therapists have reported that male are more satisfied with their jobs than females are, whereas Moon et al. (2010) reported that job satisfaction was higher in females than in males. This is thought to be because the subjects of the study by Moon et al. (2010) were physical therapists working at public medical institutions only. In other words, more female physical therapists who prefer stable occupational fields may work at public medical institutions, which are perceived as relatively more stable workplaces, and thus, job satisfaction among female physical therapists is thought to be higher. Therefore, in order to enhance the quality of medical services and customer satisfaction, workplaces that allow physical therapists to focus more on their job, with a sense of stability, should be gaining popularity. In addition, it is considered necessary for the Departments of Physical Therapy at universities to guide and encourage their students to discover their aptitudes and develop them by participating in activities that challenge as well as prepare them for their future career interests.

There were no significant correlations between job satisfaction and gender roles ( $p>05$ ). In other words, it cannot be said that biased gender role is a factor contributing to the job satisfaction of neurological physical therapists. Therefore, bias against the gender roles of neurological physical therapists should be removed and choosing an occupational field should be based on individuals' personalities and competencies rather than on gender roles.

Because the subjects of the present study were only physical therapists working at general hospitals and rehabilitation centers located in Daejeon City, South Korea and their marital status, as one of the general characteristics of the subjects, was not uniform, it is difficult to generalize the results of the present study.

\section{Conclusion}

The results of this study, it cannot be concluded that bias against gender roles is a contributing factor for neurological physical therapists being satisfied with their job, and thus bias against gender roles among neurological physical therapists should be removed. Nevertheless, with respect to differences in job satisfaction by gender, we suggest that physical therapists should be guided and encouraged to choose fields that they really want rather than to choose occupational fields that are more stable. This may be accomplished by providing them with more stable jobs, self-esteem enhancement programs, career development programs, and career counseling in the future.

\section{References}

Bae WS, Lee GC, Oh HW. Effects of the emotional suppression and burnout on the job satisfaction among physical therapists. J Korean Soc Phys Med. 2011;6(2):177-87.

Bailey AA, Hurd PL. Depression in men is associated with more feminine finger length ratio. Pers Indiv Differ. 2005;39(4):829-36.

Cho NJ, Kim BC, Seol SB, et al. A study on relationship between job stress, self-esteem and job satisfation in rehabilitation professional physical therapist. KSIM. 2013;1(1):69-76.

Evardone M, Alexander GM, Morey LC. Hormones and 
borderline personality features. Pers Individ Dif. 2008;44(1):278-87.

Jang MS, Jang HK, Jung YM. Impact of empowerment on job involvement and organizational commitment of physical therapists: have a rehabilitation medicine in hospital. Jour. of KoCon.a. 2010;10(9):293-301.

Jeon SW, Kim SH, Oh DH, et al. The correlation between 2 th to 4 th digit length ratio and characteristics of temperament and character in university students. Journal of Korean Society of Biological Psychiatry. 2010;17(3):136-44.

Jo HS. Analysis of relationship between preparation and achievement for beginning to work according to the distinction of sex of university graduates. Seoul, The Graduate School Ewha Womans University, Master's Degree. 2009.

Jo KH. Types of attitudes toward a successful life of korean nursing students: A Q methodological approach. J Korean Acad Nurs. 2008;38(1):111-21.

Jung TC. The study on internal service quality, service quality to patients, job satisfaction, organizational identification and job identification of physical therapists. J Korean Soc Phys Med. 2010;5(3):421-34.

Jung YH. A study on the effects of interest type and sex role identity in the career compromise process. Seoul, Yeonsei University, Master's Degree. 2002.

Kim $\mathrm{GH}$, Kim $\mathrm{KH}$. The influence of digit ratio on consumption behavior. Korean Journal of Counseling And Psychotherapy. 2010;11(2):183-211.

Kim KS, Jo KJ. Digit ratio (2D:4D) and gender role orientation in health and medical students. JKAIS. 2012;13(5): 2170-7.

Kim SH, Young SY, Kim MJ, et al. Direct care stress and job satisfaction in home care nurses. Korean J Women Health Nurs. 2004;10(3):261-5.

Lee HS, Song HK, Kim HN, et al. The study work conditions and job satisfaction of physical therapist in jeonnam east area. J Kor Phys Ther. 2005;17(1):80-95.
Lee JI. Effects of sex role and job characteristics on the job satisfaction and career attitudes. Jinju, Gyeongsang National University. Master's Degree. 2002.

Lee MA. Analysis of the effects of job characteristics on their job satisfaction among physical therapists. Seoul, Kyunghee University. Master's Degree. 2013.

Lee. DJ. The relationships among satisfaction in major, gender identity, and gender stereotypes of male nursing students. Seoul, Yeonsei University, Master's Degree. 2004.

Lim JD, Lee KH, Kim WJ. Influence of individual and job characteristics, professional job perception, and group cohesiveness on organizational citizenship behavior of physical therapists in hospitals. Korean Journal of Hospital Management. 2003;8(2):70-92.

Lim JD, Jang MS, Lee YC, et al. The Relationships between Job Characteristics and Empowerment, Organizational Commitment of Physical Therapist to Professionalism of Rehabilitation Service. J Korean Soc Phys Med. 2010;5(2):183-92.

Manning JT, Barley L, Walton J, et al. The 2nd:4th digit ratio, sexual dimorphism, population difference, and reproductive success for sexually antagonistic genes. Evol Hum Behav. 2000;21(3):163-83.

Moon JK, Song BK, Hwang BY. A study on job satisfaction among physical therapists in the public health centers of the Seoul metropolitan area. J Kor Phys Ther. 2010;22(2):61-8.

Park BS. A study on career preference after graduation of university students majoring in physical therapy. Sungnam, Eulji University. Master's Degree. 2012.

Park HS, Ha JH, Lee MH. The relationship among gender-role identity, gender stereotype, job satisfaction and turnover intention of male nurses. JKAIS. 2014;15(5) 2962-70.

Park JS. The relationship of organizational and job characteristics, empowerment, job satisfaction and organizational commitment perceived by hospital 
administrative staffs. HPM. 2004;14(1):65-88.

Park KS. Korean male college students' gender roles and career compromise. Seoul, Dankook University, Doctor's Degree. 2008.

Sim JH, Yoon TH. Analysis of factors that influence the job satisfaction of physical therapists. J Kor Phys Ther.
2011;23(1):67-75.

Sin JY. Motivational attributes of 'Occupational possible selves' in male and female college students' career path decisions. Seoul, The Graduate School Ewha Womans University, Master's Degree. 2010. 